\title{
Effects of nitrogen topdressing and paclobutrazol at different stages on spike differentiation and yield of winter wheat
}

\author{
Dongxiao Li ${ }^{1}$, Shaojing Mo ${ }^{1}$, William D. Batchelor ${ }^{2}$, Ruiting Cheng ${ }^{1}$, Hongguang Wang ${ }^{1}$, Ruiqi ${ }^{\text {Corresp. } 1}$ \\ 1 Hebei Agricultrual University, Baoding, China \\ 2 Auburn University, Auburn, United States of America \\ Corresponding Author: Ruiqi \\ Email address: wheatIrq@163.com
}

Background. Optimal nitrogen (N) application and plant growth regulators can improve wheat productivity. This can help to improve yield level and ensure food security with limited resources in the Huang-Huai-Hai Plain of China (HPC). Methods. A 2-year field experiment was conducted using a randomized block design with four treatments (TS- $\mathrm{N}$ topdressing at pseudostem erection stage ; TPS- $\mathrm{N}$ topdressing combined with paclobutrazol application at pseudostem erection stage; $\mathrm{TJ}-\mathrm{N}$ topdressing at jointing stage; TPJ-N topdressing at combined with paclobutrazol application at jointing stage) in 2011-2013. Results. The grain number per ear, thousand kernel weight and yield for the TJ and TPJ treatments were higher than those of the TS and TPS treatments. Grain number per ear, yield, and thousands kernel weigh for the TPJ treatment were significantly higher than for the TS and TPS in 2011-2012 (9.82\% and 7.27\%, 10.23\% and $8.99 \%, 6.12 \%$ and $5.58 \%$ ) and in $2012-2013$ ( $10.21 \%$ and $11.55 \%, 8.00 \%$ and $6.58 \%, 0.00$ and 0.00 ), respectively. Thousands kernel weight under TJ were significantly higher than those under TS and TPS by $13.21 \%$ and $14.03 \%$, respectively in 2012-2013. The floret number, significantly correlated with cytokinin content, was also significantly increased under TJ and TPJ at connectivum differentiation stage. For TPJ treatment, the floret number was significantly higher than for the TS, TPS, and TJ by $19.92 \%, 10.21 \%, 6.10 \%$ in $2011-2012$; it was higher than for the TS and TPS by $28.06 \%$ and $29.61 \%$ in $2012-2013$, respectively. The relative expression level of cytokinin oxidase/ dehydrogenase gene (TaCKX2.2) was improved during flowering, when cytokinin content was at high level and was also inhibited by paclobutrazol with different degrees. Conclusions. Therefore, nitrogen topdressing at jointing stage had increased grain number per ear, thousand kernel weight, and grain yield of wheat. Paclobutrazol could delay spike differentiation and promote cytokinin accumulation that induced expression of $\operatorname{TaCKX} 2.2$, maintaining hormonal balance and affecting wheat spike morphogenesis. 


\section{Effects of nitrogen topdressing and paclobutrazol at different stages on spike 2 differentiation and yield of winter wheat}

3 Dongxiao Li ${ }^{1}$, Shaojing Mo ${ }^{1 *}$, William D. Batchelor ${ }^{2}$, Ruiting Cheng ${ }^{1}$, Hongguang Wang ${ }^{1}$ and Rui-Qi Li ${ }^{1}$

$4{ }^{1}$ State Key Laboratory of North China Crop Improvement and Regulation / Key Laboratory of Crop Growth

5 Regulation of Hebei Province / College of Agronomy, Hebei Agricultural University, Baoding, Hebei Province, 6071000, China.

$7 \quad{ }^{2}$ Biosystems Engineering Department, Auburn University, Auburn, Alabama, 36849, United States of America

$8 *$ These authors contributed equally to this work.

9 Corresponding author. Ruiqi Li, wheatlrq@163.com

\section{Abstract.}

11 Background. Optimal nitrogen $(\mathrm{N})$ application and plant growth regulators can improve wheat productivity. This can help to improve yield level and ensure food security with limited resources in the Huang-Huai-Hai Plain of China (HPC).

Methods. A 2-year field experiment was conducted using a randomized block design with four treatments (TS- $\mathrm{N}$ topdressing at pseudostem erection stage; TPS- $\mathrm{N}$ topdressing combined with paclobutrazol application at pseudostem erection stage; $\mathrm{TJ}-\mathrm{N}$ topdressing at jointing stage; TPJ-

$17 \mathrm{~N}$ topdressing at combined with paclobutrazol application at jointing stage) in 2011-2013.

Results. The grain number per ear, thousand kernel weight and yield for the TJ and TPJ treatments were higher than those of the TS and TPS treatments. Grain number per ear, yield, and thousands 
20

21

kernel weigh for the TPJ treatment were significantly higher than for the TS and TPS in 2011$2012(9.82 \%$ and $7.27 \%, 10.23 \%$ and $8.99 \%, 6.12 \%$ and $5.58 \%)$ and in $2012-2013(10.21 \%$ and $11.55 \%, 8.00 \%$ and $6.58 \%, 0.00$ and 0.00 ), respectively. Thousands kernel weight under TJ were significantly higher than those under TS and TPS by $13.21 \%$ and $14.03 \%$, respectively in 2012 2013. The floret number, significantly correlated with cytokinin content, was also significantly increased under TJ and TPJ at connectivum differentiation stage. For TPJ treatment, the floret number was significantly higher than for the TS, TPS, and TJ by $19.92 \%, 10.21 \%, 6.10 \%$ in 2011 2012; it was higher than for the TS and TPS by $28.06 \%$ and $29.61 \%$ in $2012-2013$, respectively. The relative expression level of cytokinin oxidase/ dehydrogenase gene ( $\mathrm{TaCKX} 2.2$ ) was improved during flowering, when cytokinin content was at high level and was also inhibited by paclobutrazol with different degrees.

Conclusions. Therefore, nitrogen topdressing at jointing stage had increased grain number per ear, thousand kernel weight, and grain yield of wheat. Paclobutrazol could delay spike differentiation and promote cytokinin accumulation that induced expression of $\operatorname{TaCKX} 2.2$, maintaining hormonal balance and affecting wheat spike morphogenesis.

Keywords topdressing stages, floret number, phytohormone, spike differentiation, TaCKX2.2

\section{INTRODUCTION}

The North China Plain is one of the most important grain production regions in China and is experiencing conflicts between limited natural resources and crop production. Excessive use of nitrogen fertilizer is common in order to increase yields in the wheat-maize planting system. This 
40

often leads to large losses of nitrogen, resulting in serious environmental pollution (Azam Shah et al. 2009; Wang et al. 2010). The planting area of winter wheat has been decreasing in order to enhance ecological benefits and due to limited water available for irrigated due to historic overexploitation of ground water (Xu et al. 2005). In order to achieve China's food security goals, it is important to improve wheat yields. Wang et al. (2015) found that a key factor for increasing wheat yield was increasing the grain number per spike and seed weight, which is influenced by nitrogen fertilizer in the high-yield wheat region of Hebei Province. Nitrogen fertilizer promotes allocation of assimilate and increases assimilation amount and contribution rate of post-anthesis photosynthate to grain (Ma et al. 2008a). There are three nitrogen absorption peaks of winter wheat including fall vegetative growth before winter, the jointing-booting stage, and the flowering-filling stage. The transport of carbon assimilates to grain was found to be more efficient with nitrogen topdressing at the jointing stage than at the flowering stage (Zhai and $L i, 2006$ ). However, the nitrogen application should be delayed until booting stage under super-high-yield conditions (Kara and Uysal, 2009; Liu et al. 2019). The time of optimal nitrogen application is often related to local water conditions and wheat varieties. Under drought conditions or limited irrigation, nitrogen topdressing applied at the jointing stage was more beneficial to transport carbon photosynthate to grain compared to the flowering stage for winter wheat (Gevrek and Atasoy, 2012). However, for spring wheat, it was more beneficial to apply topdressing nitrogen at the flowering stage(Walsh et al. 2018). Under irrigated conditions, a later topdressing application enhanced photosynthesis and increased wheat yield (Chen et al. 2008).

Paclobutrazol (pp333), a plant growth regulator that inhibits synthesis of endogenous 
61

62

63

64

65

66

67

68

69

gibberellin, is easily absorbed by wheat root, stem, and leaf. The application of paclobutrazol can inhibit crop height, increase stress tolerance, promote tillering, and increase spike number and yield (Hajihashemi et al. 2007; Gómez et al. 2011; Peng et al. 2014; Dwivedi et al. 2017). Combining nitrogen topdressing with paclobutrazol can also improve photosynthetic rate, increase grain weight per spike, and achieve further increase in wheat yield when applied at the jointing stage (Yang et al. 2008). A combination of nitrogen topdressing at the pseudostem erection stage with a paclobutrazol application can increase dry matter accumulation, grain weight per spike, and grain yield (Zhang et al. 2017). The appropriate amount of nitrogen and paclobutrazol can increase stem lodging resistance, nitrogen uptake and maintain high duration of the flag leaf to promote high and stable yield (Chen et al. 2011; Nouriyani et al. 2012a,b). Paclobutrazol also regulated root morphological characteristics, maintained physiological function and root activity, increased grain yield by enhancing the levels of osmolytes, endogenous hormone contents, and antioxidant activities under adverse environmental conditions (Soumya et al. 2017; Kamran et al. 2018). Additionally, nitrogen can also regulate endogenous hormone content and affect ear and flower development (Ma et al. 2008a). Spikelet number, regulated by hormones in spike and roots, was closely related to nitrogen supply (Chen et al. 2008; Zhang et al. 2009). At the early grain formation stage, zeatin riboside (ZR) content could effectively regulate panicle flower development and spikelet number (Ma et al. 2008a). Decreasing free cytokinin (mainly zeatin and zeatin riboside) and $\mathrm{ABA}$ contents in grain and root would be possible resulting in sterile spikelet (Chen et al. 2008; Zhang et al. 2009). Paclobutrazol application could influence gibberellins (GAs) directly and modify flowering and development of plants (Zhang et al. 2016). 
82 During ear differentiation, cytokinins oxidase/dehydrogenase (CKX), controlling

83

endogenous cytokinins content, often negatively regulates time of flowering and grain formation of crops (Zalewski et al. 2010; Yeh et al. 2015; Ashikari et al. 2005; Bartrina et al. 2011). For wheat, TaCKX2.2 was involved in the formation of the spike grain number and yield (Zhang et al. 2011). Inhibiting TaCKX2 expression by RNAi increased the grain number per spike in bread wheat plants (Li et al. 2018). Previous studies have shown that the optimal application amount of a nitrogen and paclobutrazol combination at the stem elongation stage (Nouriyani et al. 2012a,b) and nitrogen topdressing at the jointing stage was advantageous for yield and grain quality ( $W u$ et al., 2014). It is not clear what the optimum topdressing nitrogen combined paclobutrazol application is for optimal ear differentiation and individual wheat productivity, nor how changing phytohormones and related gene expression occur in plants under different nitrogen topdressing treatments in the North China Plain.

Our hypothesis was that nitrogen topdressing and paclobutrazol application at different stages would influence cytokinin (IPA and ZR) content of spike differentiation. Accordingly, the related gene expression varied. Combining molecular biology methods and crop growth analysis, we explored the differential expression law of cytokinin synthesis related genes in individual spike differentiation that directly influence grain yield. The objective of this study was to 1) evaluate the effect of topdressing nitrogen with paclobutrazol application on spike differentiation, and 2) elucidate the possible mechanisms of improving the productivity of wheat. The focus of this study was to determine the impact of $\mathrm{N}$ and paclobutrazol on individual spikelet formation, resulting differences in final yield, and to determine how phytohormones and related gene expression 
103 changes during spike differentiation. This study will help to provide guidance for optimizing

104 fertilizer and increasing high yield potential of wheat in the North China Region.

105 Materials and methods

106 Experimental site and soil

107 A field experiment was carried out from 2011 to 2013 on super-high-yield testing farmland in

108 Gaocheng, Shijiazhuang $\left(37^{\circ} 79^{\prime} \mathrm{N}, 115^{\circ} 31^{\prime} \mathrm{E}\right)$, China. The climate was classified as subhumid 109 continental monsoon. The mean annual rainfall is typically less than $520 \mathrm{~mm}$, one-third of which typically falls during the wheat-growing season. Winter wheat-summer maize rotation is the typical planting system in this region. The soil type was light-loamy Chao Soil and the soil properties are shown in Table 1.

Experimental design and crop management

The experiment was a randomized complete block design with four experimental treatments:

1) nitrogen topdressing at pseudostem erection stage (TS), 2) TS with paclobutrazol application at

pseudostem erection stage (TPS), 3) nitrogen topdressing at the jointing stage (TJ), and 4) TJ with paclobutrazol application at the jointing stage (TPJ). Each treatment was replicated three times. Each plot area was $60 \mathrm{~m}^{2}$.

The cultivar Shimai18 was provided by Shijiazhuang Academy of Agricultural Sciences, Shijiazhuang, Hebei. This variety was planted on October 7, 2011 and October 9, 2012 with a row spacing of $0.15 \mathrm{~m}$ and plant density of $270 \diamond 10^{4}$ plants $^{-1}$. Fertilizers were applied before planting

122 at rates of $112 \mathrm{~kg} \mathrm{ha}^{-1}$ nitrogen, $60 \mathrm{~kg} \mathrm{ha}^{-1}$ phosphorus, $87 \mathrm{~kg} \mathrm{ha}^{-1}$ potassium and $9 \mathrm{~kg} \mathrm{ha} \mathrm{zinc}^{-1}$.

123 Topdressed $\mathrm{N}$ was applied at either pseudostem erection stage or jointing at a rate of $112 \mathrm{~kg} \mathrm{ha}^{-1}$. 
124 Fore-rotating corn straw from the previous crop was crushed 2 times and returned to the field at a

$12515 \mathrm{~cm}$ depth. Paclobutrazol (provided by Shenggong Bioengineering (Shanghai) Co., LTD) was

126 applied by a foliar spray of aqueous solution containing $10 \%$ wettable powder at an effective

127 concentration of $200 \mathrm{mg} \mathrm{kg}^{-1}$ which equated to a rate of $675 \mathrm{~kg} \mathrm{ha}^{-1}$ at either pseudostem erection

128 or jointing stage.

129 Variable measurements

130 Young ears were sampled and then quickly-frozen at $-80^{\circ} \mathrm{C}$ in the differentiation stages of

131 stamen and pistils, early connectivum, late connectivum, and tetrad formation, separately. Partial

132 young ears marked on the same flowering date were sampled at 0, 3, 6, 9 and 12 days after

133 flowering. Beginning with the regreening stage, representative wheat plants were selected at 3

134 days intervals. The numbers of spikelets and florets were recorded in a constant state (on about

$13521^{\text {st }}$ April) using an anatomical lens (Stemi 2000-c, Germany).

136 Total ribonucleic acid (RNA) was extracted from wheat samples with a PlantRNA Kit

137 (Tiangen, Beijing, China) according to the manufacturer's protocol. RNA concentration and purity

138 were detected by spectrophotometer (Nanodrop, USA); the RNA integrity was detected by agarose

139 gel electrophoresis. cDNA obtained by reverse transcription of RNA was used for subsequent

140 fluorescence quantitative expression. First-strand cDNA was generated from $2 \mu \mathrm{g}$ of total RNA

141 using a PrimeScript II First Strand cDNA Synthesis Kit (TaKaRa, Dalian, China). The primer used

142 for qRT-PCR were designed according to the published sequence TaCKX2 (geneID: GU084177.1)

143 by software Primer 5 (Zhang et al., 2011). Priming sequence: GGGAGAAGAAGCACTTTGGTC

144 (TaCKX2.2-F); CCTGCAGTAAACTCAAACCATATC (TaCKX2.2-R). The optimal reference 
146 CCAGTGCTGCTTGGAATGATG) was selected for mRNA transcription studies using 147 quantitative real-time polymerase chain reaction (PCR). All PCR reactions were repeated three times and the data were normalized to constitutively expressed TaGAPDH according to the 2$\Delta \Delta \mathrm{Ct}$ method described by Livak and Schmittgen (2001). Thermal-cycling conditions included an initial denaturation at $95^{\circ} \mathrm{C}$ for $5 \mathrm{~s}$, followed by 45 cycles at $95^{\circ} \mathrm{C}$ for $5 \mathrm{~s}, 60^{\circ} \mathrm{C}$ for $10 \mathrm{~s}$, and $72^{\circ} \mathrm{C}$ for $15 \mathrm{~s}$, then a final melt step from $60^{\circ} \mathrm{C}$ to $95^{\circ} \mathrm{C}$. Endogenous phytohormone content (IAA, auxin; ABA, abscisic acid; GA, gibberellin; cytokinin, CTK including isopentenyl adenosine-IPA and trans zein nucleoside-ZR) was measured by enzyme linked immunosorbent assay (ELISA) (Li et al., 2017). The test kit was provided by College of Agriculture and Biotechnology, China Agricultural University, Beijing, China. Young ear samples were collected from each treatment and cut into $0.5 \mathrm{~g}$ pieces and were ground to a fine powder in liquid nitrogen with a pre-cooled mortar. The powder was diluted with extracting solution and was extracted over $4 \mathrm{~h}$ at $4{ }^{\circ} \mathrm{C}$ in cold $80 \%$ methanol based on the protocol outlined by Oliver et al. (2007). The homogenate was then centrifuged at $3500 \mathrm{rpm} \mathrm{min}^{-1}$ for $20 \mathrm{~min}$, and the supernatant was collected and washed by $80 \%$ methanol in a C-18 solid phase extraction column. Next, the filtered fluid of all the samples was pooled and dried in a vacuum chamber.

Sample diluent was added to a final volume of $1 \mathrm{~mL}$, which was diluted in tris-buffered saline and 
166

167

168

169

170

171

172

173

174

175

176

177

178

179

180

181

182

183

184

185

area was $3 \mathrm{~m}^{2}$ for each plot. All plants were harvested, threshed, and dried to weigh seed yield.

And 1000-kernel weight was determined using the sum of two 500-kernel sample weights according with absolute value of the difference between two 500-kernel weights divided the average of both was less than 5\%. If not, the third 500-kernel sample was weighted. The number of spikes was measured by counting the samples in one-meter-length of row in each replication at maturity. The number of kernels per spike was measured by counting the number of kernels per spike in 20 plants per plot.

\section{Statistical analysis}

All data were run using analysis of variance (ANOVA) with three replicates according to Excel 2003, SPSS17.0 (SPSS Inc., Chicago, USA). The Duncan's new Multiple Range (DMR) test at 5\% probability level was used to test the differences among the mean values. Significant differences were labelled based on DMR.

\section{RESULTS}

\section{Plant height}

Plant height increased gradually with the growth and development of seedlings in all treatments (Table 2). At pseudostem erection stage, there were no significant differences in plant height across all treatments. At the jointing stage, plant height in the TS treatment was significantly higher than in the TPS, TJ (2011-2012) and TPJ treatments (2011-2012). Plant height in the TJ and TPJ treatments were not significantly different. At booting stage, the plant height in the TS treatment was significantly higher than other treatments, while the TPJ treatment had significantly lower 
plant height than other treatments (2012-2013). No significant differences were existed between

187 TPS and TJ. At mature stage, plant height reached to a peak value for all treatments. The 188 paclobutrazol treatments had a significantly lower plant height than the non-paclobutrazol 189 treatments.

190

191

\section{Wheat yield and yield components}

Data from both years showed that grains per spike, thousand grain weight, and yield of wheat in the TJ and TPJ treatments were higher than those in the TS and TPS treatments (Table 3). The decreasing order of observed yield was TPJ $>$ TJ $>$ TPS $>$ TS, and the TPJ yield was significantly higher than the yield for the TPS (10.22\% and 8.88\% higher) and TS (8.99\% and $6.58 \%$ higher) treatments in 2011-2012 and 2012-2013, respectively. The topdressing $\mathrm{N}+$ paclobutrazol treatment yield components were not significantly different than the $\mathrm{N}$ treatments alone for the different paclobutrazol application dates. The thousand grain weight for the TJ and TPJ treatments were significantly higher than for the TS by $3.57 \%$ and $6.12 \%$, respectively, and TPJ was significantly higher than TPS by 5.58\% in 2011-2012. Thousand grain weight in the TJ treatment was significantly higher than in the TS and TPS treatments by $13.21 \%$ and $14.03 \%$, respectively, in 2012-2013. This result suggested that nitrogen topdressing at the jointing stage was more beneficial to grain weight than at the pseudostem erection stage. The grains per spike in TJ and TPJ were significantly higher than in TS and TPS in 2011-2012, while grains per spike in TPJ was significantly higher than in TS and TPS in 2012-2013. Grains per spike for the TJ treatment was significantly higher than that of TPS in 2012-2013. There were no significant differences in spikes 
per $\mathrm{hm}^{2}$ among four treatments.

\section{Spike differentiation}

208 The numbers of spikelets and florets in the TPS treatment were less than those in other treatments

209 (Table 4). Spikelet number in the TS treatment, the most one, was significantly higher than in the 210 TPS treatment by $8.33 \%$ and $5.43 \%$ in $2011-2012$ and 2012-2013, respectively. But spikelet 211 number in the TS had no obvious differences with that in the TJ and TPJ treatments. Florets number 212 in the TPJ was significantly higher than in the TPS and TS treatments by $8.68 \%$ and $6.68 \%$ in 2011 213 2012; and florets number in the TPS treatment was significantly lower than in the other treatments

214 in 2012-2013. The number of florets differentiated from stamen and pistil of wheat in the TPJ 215 treatment was significantly higher than in the TJ (2011-2012, 7.11\% higher), TS (4.39\% and $21614.49 \%$ higher), and TPS (20.94\% and 18.05\% higher) treatments, respectively; this number in the 217 TJ was significantly higher than in the TPS and TS treatments by $13.28 \%$ and $16.81 \%$ in $2012-$ 218 2013, respectively. The floret number at the connectivum differentiation stage in the TPJ treatment 219 was significantly higher than in the TS, TPS, and TJ treatments by $19.92 \%, 10.21 \%$, and $6.10 \%$, 220 respectively, in 2011-2012; and the numbers in the TJ and TPJ were significantly higher than in

221 the TS (30.75\% and 28.06\%) and TPS (32.33\% and 29.61\%) treatments in 2012-2013, 222 respectively. These results suggested that $\mathrm{N}$ topdressing and paclobutrazol application at jointing 223 stage was more helpful in improving development of florets, inhibiting its degeneration in wheat, 224 and increasing grains number per spike.

\section{Phytohormone content}


226 The variation of endogenous hormone levels in wheat spikes were similar among all treatments

227 during differentiation of the main stem spike (Fig.1). However, the content of endogenous

228 hormones was different at various phases of spike differentiation. The changes in CTK, IAA, and

229 GA content showed a single-peak curve. CTK contents in the TS and TJ treatments was

230 significantly higher than in the TPS (18.52\% and 17.78\%) and TPJ (17.65\% and 16.91\%),

231 respectively, at the double-ridge stage. The peak value of CTK content in the TS treatments was

232 significantly higher than in the TPS treatment by $12.48 \%$ at the stamen and pistil differentiated

233 stage, when CTK content in the TPS was significantly higher than in the TJ and TPJ by $12.64 \%$

234 and $13.17 \%$, respectively. The peak values of GA in the TS and TPS were significantly higher than

235 in the TJ (37.12\% and 29.60\%) and TPJ (37.64\% and 30.09\%) treatments, respectively, at the

236 floret primordia differentiation stage. IAA content in the TS and TPS treatments were significantly

237 higher than in the TJ (15.04\% and 7.02\%) and TPJ (25.98\% and $17.19 \%)$ treatments, respectively,

238 at the pistil and stamen differentiated stage. These results showed that the nitrogen topdressing at

239 the pseudostem stage promoted accumulation of growth acceleration hormones more than at the

240 jointing stage. The differences between TS and TPS and between TJ and TPJ were increasingly

241 smaller during the panicle differentiation stage. ABA content in spikes showed an increasing trend

242 throughout the growth period. At the tetrad stage, ABA reached the maximum value and showed

243 a descending order of TS $>$ TPS $>$ TJ $>$ TPJ; ABA contents in the TS and TPS treatments were

244 significantly higher than in the TJ $(18.22 \%$ and $13.69 \%)$ and TPJ $(34.07 \%$ and $28.93 \%)$ treatments,

245 respectively. These results suggested that ABA content could be decreased under nitrogen

246 topdressing with paclobutrazol application at the jointing stage.

PeerJ reviewing PDF | (2021:06:62575:2:0:NEW 15 Oct 2021) 

TS (14.15\% and $15.41 \%)$ and TJ (24.54\% and $25.91 \%)$ treatments, respectively, at tetrad stage. and $16.62 \%)$ and TPS (29.75\% and 25.64\%) treatments, respectively, at 12 days after flowering.

15 days after flowering.

\section{TaCKX2.2 Expression}

The trend of TaCKX2.2 expression is shown in Fig. 3 under different treatments during spike development. From the stamen and pistil differentiation to tetrad differentiation stage, the expression level of $\operatorname{TaCKX} 2.2$ was very low in all treatments. The level rose sharply and reached a peak on 6 days after flowering under the TS and TPS treatments, which were significantly lower 
267 than the TJ $(65.22 \%$ and $69.27 \%)$ and TPJ $(69.67 \%$ and $73.21 \%)$ treatments, respectively. From

268 0-12 days after flowering, the TaCKX2.2 expression in spikes under the TJ and TPJ treatments

269 was significantly higher than that under the TS and TPS treatments, respectively. The first peak

270 for the TJ and TPJ treatments occurred on 0 days and the second higher peak occurred on 6 days

271 after flowering. At 9 days after flowering, TaCKX2.2 expression was decreased substantially in all

272 treatments. These results suggested that TaCKX2.2 expression could be induced by paclobutrazol

273 at the jointing stage and its expression in TPJ reached a maximum value during the flowering

274 stage.

\section{Correlation Analysis} days after flowering (Table 5). At 0,6, and 12 days after flowering, the florets numbers from the stamen and gynoecium and from connectivum were all very significantly correlated to cytokinin (IPA+ZR) content. At 3, 9, and 15 days after flowering, there was a significant correlation between cytokinin (IPA+ZR) content and numbers of florets differentiated from stamen and gynoecium (15 days exception) and from connectivum. These results showed that both IPA and ZR could control and regulate floret number and development during full-blossom period.

\section{DISCUSSION}

284 It has been reported that nitrogen topdressing at the jointing stage can increase the number of grains 285 per ear and wheat yield (Li et al. 2010). The application of paclobutrazol at the stem elongation 286 stage can promote nitrogen uptake and reduce nitrogen leaching to improve nitrogen use efficiency 
287 and wheat yield (Nouriyani et al. 2012b). In this study, the number of grains per ear, thousand

288 kernel weight, and yield of wheat in the TPJ treatment were significantly higher than those in the

289 TS and TPS treatments, which was in agreement with the report of Wu et al. (2014). Paclobutrazol

290 application decreased plant height from booting stage to maturity stage, and further reduced plant

291 height when the application time was delayed from the pseudostem erection stage to the jointing

292 stage. The inhibitory effect of paclobutrazol on overgrowth of wheat plants likely reduced excess consumption of nutrients and reserved photosynthate accumulation to support grain growth (Ghosh

294 et al., 2010). Combing nitrogen topdressing and paclobutrazol application at jointing stage increased wheat yield. Although a single application of paclobutrazol had no significant effect on yield and yield components, using topdressing nitrogen with paclobutrazol gave higher yield component values than treatments without the paclobutrazol application. It was reported that the best effect was achieved using a combination of $150 \mathrm{mg} \mathrm{L}^{-1}$ of paclobutrazol and $160 \mathrm{~kg} \mathrm{ha}^{-1}$ nitrogen, for which paclobutrazol increased the absorption and transportation of nitrogen in plant and significantly affected photosynthetic pigments to maintain a high duration of flag leaf area which increased the grain yield (Nouriyani et al. 2012a). Paclobutrazol was found to also reduce plant height and flag-leaf area of black rice, but increased sucrose and amylopectin content in the grain at a concentration of $50 \mathrm{ppm}$ (Dewi and Darussalam, 2018). Previous reports indicated that paclobutrazol was prone to regulation on physiological balance at early growth stages, but not on final yield of winter wheat directly (Yang et al. 2008). Therefore, the regulatory effect of paclobutrazol is different for different developmental phase of plants and concentration variation from paclobutrazol or nitrogen or both. 
Further observations have shown that the differentiation of young panicles was inhibited and the

floret number was decreased under nitrogen topdressing with paclobutrazol at the pseudostem

erection stage compared with the jointing stage. This may explain why grain number per ear and

yield of wheat with nitrogen topdressing at the pseudostem erection stage was lower than at

jointing stage. It is known that the growth of young ears and development of spikelets is closely

related to hormone content (Zhang et al. 2009). A recent study reported that paclobutrazol elevated

endogenous auxin and abscisic acid levels, suppressed gibberellins (GA4) and trans-zeatin

significantly decreased the content of GA3 and IAA, and increased ABA contents in leaves of

wheat (Aly et al. 2011). This study indicated that the paclobutrazol application decreased the

number of spikelets and florets at the pseudostem erection stage, but increased floret number at

324 GA content during spike differentiation but also CTK, IAA, and ABA content before the tetrad 
329

330

331

332

333

334

335

336

337

338

339

340

341

342

343

344

345

346

347

348

349

without paclobutrazol at the jointing stage compared with the pseudostem erection stage. This result suggested that the differences in number of spikelets and florets among all treatments were not primarily determined by the phytohormone levels at this stage. At the tetrad stage, ABA content in spikelets under the TPS treatment was higher than that under the TPJ stage, suggesting that other promoting hormones likely regulated panicle and floret development after the tetrad stage. These results have also verified the hypothesis that individual spikelets number was affected by both nitrogen topdressing and paclobutrazol application, which played a promoting role mainly during the jointing stage.

Cytokinin, which is degraded by cytokinin oxidizes/dehydrogenase to IPA and ZR, plays an important role in early spikelet development and panicle differentiation (Ma et al. 2008b; Jameson et al. 2015). From the tetrad to anthesis stage, cytokinin content in spikelets may be a regulatory mechanism. At the tetrad stage, ZR content in spikelets under the nitrogen topdressing with paclobutrazol treatment was significantly higher than that without the paclobutrazol application, which help to increase yield sink capacity (Dewi and Darussalam, 2018). From this stage onwards, the contents of ZR and IPA and the expression level of TaCKX2.2 were higher for the nitrogen topdressing during $0-6$ days after flowering. The increment was higher at the jointing stage than at the pseudostem erection stage. It is likely that cytokinin oxidation/dehydrogenase would perform stronger degradation to maintain hormone balance when accumulation of cytokinin in ear exceeded demand, which often results from the rapid development of wheat ears with nitrogen topdressing during reproductive growth (Werner et al. 2006; Zhang et al. 2011). Panicle development was faster under nitrogen topdressing at the jointing stage, when TaCKX2.2 
350

351

352

353

354

355

356

357

358

359

360

361

362

363

364

365

366

367

368

369

expression was higher than that at the pseudostem erection stage. Meantime, paclobutrazol application increased $\operatorname{TaCKX} 2.2$ expression to inhibit cytokinin content. Our study showed that the contents of IPA and ZR in the TPJ treatment, and ZR and (IPA+ZR) in the TPS treatment at 3 and 9 days after flowering, respectively, were suppressed by paclobutrazol, which was partly consistent with Opio et al. (2020). However, the contents of ZR and ZR + IPA in TPJ were elevated significantly by paclobutrazol at 3 days after flowering. These results can be interpreted that paclobutrazol induced early flowering by increasing ABA and cytokinins contents in buds, which regulated increases in leaf water potential and carbon-nitrogen ratio of mango (Upreti et al. 2013). This study also showed that cytokinin (IPA+ZR) content was significantly correlated with the floret number at the stamen and gynoecium and the connectivum differentiation stage. It was established that paclobutrazol regulates floret differentiation and development indirectly by regulating cytokinin content and influencing the final yield. These results further verified the hypothesis that spikelet number and differentiation was regulated by phytohormone, in which cytokinin (IPA and ZR) content and $T a C K X 2.2$ expression could keep homeostasis mainly after the tetrad stage. Other factors such as water status, paclobutrazol concentrations, and growth stage should also be considered in understanding the regulatory process. Additionally, the differences in gene expression in spikes among treatments was not only influenced by cytokinin content but also by multiple hormone interactions and other hormone levels changing at crucial stages. Further research is needed to determine the primary molecular mechanisms by which assimilate of grain increased for the nitrogen and paclobutrazol treatment. 
370

371

372

373

374

375

376

377

378

379

380

381

382

383

384

385

386

387

388

389

\section{Conclusion}

In conclusion, nitrogen topdressing at jointing stage was optimal for increasing floret number, kernels number per spike, and yield. And this result was partly related to cytokinin (especial ZR) content increasing after tetrad stage. Application of paclobutrazol could delay spike development to some extent and promote cytokinin content elevation, along with $\mathrm{TaCKX} 2.2$ relative expression increasing, likely to keep hormonal equilibrium and regulate spikelet and floret number. This work has systematically combined the molecular biology, phytohormone physiology and crop growth to analyze seed yield increasing approach. Future research on the deep mechanism of interaction between paclobutrazol and phytohormone is needed. Therefore, our study shows still an effective measure to promote wheat productivity by regulating individual spikelet differentiation with nitrogen topdressing and paclobutrazol application at jointing stage. And for conventional production wheat variety, there also need adequate planting population to achieve high yield and ensure food security in the North China Plain.

\section{ADDITIONAL INFORMATION AND DECLARATIONS}

\section{Funding}

This work was supported by the National System of Modern Agriculture Industrial Technology Project (CARS-03-05); the National Key Research and Development Program of China (2017YFD0300909); the Scientific Research Project of Hebei Education Department (QN2019046); the Hebei Province Natural Science Foundation for Youth (C2019204358). Science and Technology Program of Baoding (1911ZN010). the National Natural Science Foundation of 
390

391

392

393

394

395

396

397

398

399

400

401

402

403

404

405

406

407

408

409

410

China (No. 31871569).

\section{Competing Interests}

The authors declare there are no competing interests.

\section{Author Contributions}

- Dongxiao Li conceived and designed the experiments, performed the experiments, analyzed the data, prepared figures and/or tables, authored or reviewed drafts of the paper, and approved the final draft.

- Shaojing Mo analyzed the data, authored or reviewed drafts of the paper.

- William D. Batchelor improved English language and reviewed the manuscript.

- Ruiting Cheng and Hongguang Wang analyzed the data, authored or reviewed drafts of the paper, and approved the final draft

- Ruiqi Li conceived and designed the experiments, authored or reviewed drafts of the paper, funding, and approved the final draft.

\section{References}

Aly AA, Latif HH. 2011. Differential effects of paclobutrazol on water stress alleviation through electrolyte leakage, phytohormones, reduced glutathione and lipid peroxidation in some wheat genotypes (Triticum aestivum L.) grown in-vitro. Romanian Biotechnological Letters 16: 6710-6721.

Ashikari M, Sakakibara H, Lin S, Yamamoto T, Takashi T, Nishimura A, Angeles ER, Qian Q, Kitano H, Matsuoka M. 2005. Cytokinin oxidase regulates rice grain production. Science 309: 741-745.

Azam SS, Mahmood SS, Mohammad W, Shafi M, Nawaz H. 2009. N uptake and yield of wheat as influenced by integrated use of organic and mineral nitrogen. International Journal of Plant Production 3: 45-56. 
411

412

Bartrina I, Otto E, Strnad M, Werner T, Schmülling T. 2011. Cytokinin regulates the activity of reproductive meristems, flower organ size, ovule formation, and thus seed yield in Arabidopsis thaliana. The Plant Cell 23: 69-80.

Chen X, Tong YA, Kang HH, Yu JB, Wang ZH, Yang JF. 2008. Effect of postponing N application on the yield, apparent N recovery and $\mathrm{N}$ absorption of winter wheat. Plant Nutrition and Fertilizer Science 14: 450-455.

Chen XG, Shi YH, Wang CY, Yin YP, Wang ZL. 2011. Effects of nitrogen and pp333 application on the lignin synthesis of stem in relation to lodging resistance of wheat. Scientia Agricultura Sinica 44: 3529-3536.

Dewi K, Darussalam. 2018. Effect of paclobutrazol and cytokinin on growth and source-sink relationship during grain filling of black rice Oryza sativa L. "Cempo Ireng". Indian Journal of Plant Physiology 23: 507-515.

Dwivedi SK, Arora A, Kumar S. 2017. Paclobutrazol-induced alleviation of water-deficit damage in relation to photosynthetic characteristics and expression of stress markers in contrasting wheat genotypes. Photosynthetica 55: 351-359.

Ferrante A, Savin R, Slafer GA. 2010. Floret development of durum wheat in response to nitrogen availability. Journal of Experimental Botany 61: 4351-4359.

Gevrek MN, Atasoy GD. 2012. Effect of post anthesis drought on certain agronomical characteristics of wheat under two different nitrogen application conditions. Turkish Journal of Field Crops 17: 19-23.

Ghosh A, Chikara J, Chaudhary DR, Prakash AR, Boricha G, Zala A. 2010. Paclobutrazol arrests vegetative growth and unveils unexpressed yield potential of Jatropha curcas. Journal of Plant Growth Regulation, 29: 307-315.

Gómez M, Castro PA, Mignone C, Bertero H. 2011. Can yield potential be increased by manipulation of reproductive partitioning in quinoa (Chenopodium quinoa)? Evidence from gibberellic acid synthesis inhibition using Paclobutrazol. Functional Plant Biology 38: 420-430.

Hajihashemi S, Kiarostami K, Saboora A, Enteshari S. 2007. Exogenously applied paclobutrazol modulates growth in saltstressed wheat plants. Plant Growth Regulation 53: 117-128. 
432
Hampton JG, Hebblethwaite PD. 2006. The effect of the growth regulator paclobutrazol (PP333) on the growth, development and yield of Lolium perenne grown for seed. Grass and Forage Science 40: 93-101.

Jameson PE, Song J. 2015. Cytokinin: A key driver of seed yield. Journal of Experimental Botany 67: 593-606.

Jin SX, Kanagaraj A, Verma D, Lange T, Daniell H. 2011. Release of hormones from conjugates: chloroplast expression of bglucosidase results in elevated phytohormone levels associated with significant increase in biomass and protection from aphids or whiteflies conferred by sucrose esters. Plant Physiology 155: 222-235.

Kamran M, Wennan S, Ahmad I, Meng XP, Cui WW, Zhang XD, Mou SW, Aaqil K, Han QF, Liu TN. 2018. Application of paclobutrazol affect maize grain yield by regulating root morphological and physiological characteristics under a semi-arid region. Scientific Reports 8: 4818 .

Kara B, Uysal N. 2009. Influence on grain yield and grain protein content of late-season nitrogen application in triticale. Journal of Animal and Veterinary Advances 8: 579-586.

Li DX, Zhang D, Wang HG, Li YM, Li RQ. 2017. Physiological response of plants to polyethylene glycol (PEG-6000) by exogenous melatonin application in wheat. Zemdirbyste-Agriculture, 104: 219-228.

Li RN, Wang LY, Zhang YC, Liu MC, Zhai CX, Chen LL. 2010. Effect of topdressing time of nitrogen fertilizer and controlledrelease coated urea on winter wheat yield and apparent nitrogen recovery rate. Chinese Journal of Eco-Agriculture 18: 277280.Li YL, Song GQ, Gao J, Zhang SJ, Zhang RZ, Li W, Chen ML, Liu M, Xia XC, Risacher T, Genying L. 2018. Enhancement of grain number per spike by RNA interference of cytokinin oxidase 2 gene in bread wheat. Hereditas $155: 33$.

Liu ZX, Gao F, Liu Y, Yang JQ, Zhen XY, Li XX, Li Y, Zhao JH, Li JR, Qian BC, Yang DQ, Li XD. 2019. Timing and splitting of nitrogen fertilizer supply toincrease crop yield and efficiency of nitrogenutilization in a wheat-peanut relay intercroppingsystem in China. Crop Journal 7: 101-112.

Livak KJ, Schmittgen TD. 2001. Analysis of relative gene expression data using real-time quantitative PCR and the 2-DDCT 
453

454

455

456

457

458

459

460

461

462

463

464

465

466

467

468

469

470

471

472

473

method. Methods 25: 402-408.

Ma DY, Guo TC, Wang CY, Zhu YJ, Song X, Wang YH, Yue YJ. 2008. Effects of nitrogen application rates on accumulation, translocation, and partitioning of photosynthate in winter wheat at grain filling stage. Acta Agronomica Sinica 34: 10271033.

Ma ZB, He JG, Wang XC, Ma XM. 2008. Effects of nitrogen forms on endogenous hormones content in grains of two wheat cultivars. Scientia Agricultura Sinica 41: 63-69.

Nouriyani H, Majidi E, Seyyednejad SM, Siadat SA, Naderi A. 2012a. Evaluation of interaction of paclobutrazol and nitrogen on correlation between yield and photosynthetic pigments contents in two wheat cultivars (Triticum aestivum L.). Research on Crops 13: 446-452.

Nouriyani H, Majidi E, Seyyednejad S.M, Siadat SA, Naderi A. 2012b. Evaluation of nitrogen use efficiency of wheat (Triticum aestivum L.) as affected by nitrogen fertilizer and different levels of paclobutrazol. Research on Crops 13: 439-445.

Oliver SN, Dennis ES, Dolferus R. 2007. ABA regulates apoplastic sugar transport and is a potential signal for cold-induced pollen sterility in rice. Plant and Cell Physiology 48: 1319-1330.

Opio P, Tomiyama H, Saito T, Ohkawa K, Ohara H, Kondo S. 2020. Paclobutrazol elevates auxin and abscisic acid, reduces gibberellins and zeatin and modulates their transporter genes in Marubakaido apple (Malus prunifolia Borkh. var. ringo Asami) rootstocks. Plant Physiology and Biochemistry 155: 502-511.

Peng D, Chen X, Yin Y, Lu K, Yang W, Tang Y, Wang Z. 2014. Lodging resistance of winter wheat (Triticum aestivum L.): Lignin accumulation and its related enzymes activities due to the application of paclobutrazol or gibberellin acid. Field Crops Research 157: 1-7.

Soumya PR, Kumar P, Pal M. 2017. Paclobutrazol: a novel plant growth regulator and multi-stress ameliorant. Indian Journal of Plant Physiology 22: 267-278. 
474

475

476

477

478

479

480

481

482

483

484

485

486

487

488

489

490

491

492

493

494

Upreti KK, Reddy YTN, Prasad SRS, Bindu GV, Jayarama HL, Rajan S. 2013. Hormonal changes in response to paclobutrazol induced early flowering in mango cv. totapuri. Scientia Horticulturae 150: 414-418.

Walsh OS, Shafian S, Christiaens RJ. 2018. Nitrogen fertilizer management in dryland wheat cropping systems. Plants 7: 1-11.

Wang HG, Li DX, Li YM, Li RQ. 2015. Yield components and population and individual characteristics of growth and development of winter wheat over $10000 \mathrm{~kg} \cdot \mathrm{hm}^{-2}$ in Hebei Province. Scientia Agricultura Sinica 48: 2718-2729.

Wang HY, Ju XT, Wei YP, Li BG, Zhao LL, Hu KL. 2010. Simulation of bromide and nitrate leaching under heavy rainfall and high-intensity irrigation rates in North China Plain. Agricultural Water Management 97: 1646-1654.

Werner T, Köllmer I, Bartrina I, Holst K, Schmülling T. 2006. New insights into the biology of cytokinin degradation. Plant Biology 8(3): 371-381.

Wu H, Chen HZ, Zhang YK, Zhang YP, Zhu DF, Xiang J. 2019. Effects of 1-aminocyclopropane-1-carboxylate and paclobutrazol on the endogenous hormones of two contrasting rice varieties under submergence stress. Plant Growth Regultion 87: 109-121.

Wu JH, Zhang XP, Cheng RT, Hu YG, Wang XY. 2014. Effectes of nitrogen topdressing and paclobutrazol spraying different growth stages on quality and yield of wheat. Journal of. Agricultural University of Hebei 37: 8-11.

Xu YQ, Mo XG, Cai YL, Li XB. 2005. Analysis on groundwater table drawdown by land use and the quest for sustainable water use in the Hebei Plain in China. Agricultural Water Management 75: 38-53.

Yang ZY, Fan CH, Guo PY. 2008. Regulation of paclobutrazol and N fertilizer on physiology function of winter wheat leaves. Plant Nutr. Journal of Plant Nutrition and Fertilizer 14: 947-950.

Yeh SY, Chen HW, Ng CY, Lin CY, Tseng TH, Li WH, Ku MSB. 2015. Down-regulation of cytokinin oxidase 2 expression increases tiller number and improves rice yield. Rice 8: 36 .

Zalewski W, Galuszka P, Gasparis S, Orczyk W, Nadolska-Orczyk A. 2010. Silencing of the $H v C K X 1$ gene decreases the 
495

496

497

498

499

500

501

502

503

504

505

506

507

508

509

510 cytokinin oxidase / dehydrogenase level in barley and leads to higher plant productivity. Journal of Experimental Botany 61:

$1839-51$.

Zhai BN, Li SX. 2006. Study on the key and sensitive stage of winter wheat responses to water and nitrogen coordination. Journal of Integrative Agriculture 5: 50-56.

Zhang H, Tan G, Yang L, Yang J, Zhang J, Zhao B. 2009. Hormones in the grains and roots in relation to post-anthesis development of inferior and superior spikelets in japonica/indica hybrid rice. Plant Physiology and Biochemistry 47: 195204.

Zhang JP, Liu WH, Yang XM, Gao AN, Li XQ, Wu XY, Li LH. 2011. Isolation and characterization of two putative cytokinin oxidase genes related to grain number per spike in wheat. Molecular Biology Reports 38: 2337-2347.

Zhang SW, Zhang D, Fan S, Du LS, Shen YW, Xing LB, Li YM, Ma JJ, Han MY. 2016. Effect of exogenous ga3 and its inhibitor paclobutrazol on floral formation, endogenous hormones, and flowering-associated genes in 'fuji' apple (Malus domestica borkh.). Plant Physiology and Biochemistry 107: 178-186.

Zhang X, Li HR, Bu DN, Li YM. 2017. Effect of spring application of nitrogen and paclobutrazol on growth and development and yield of winter wheat. Journal of Triticeae Crops 37: 769-776. 


\section{Table $\mathbf{1}$ (on next page)}

Soil conditions of the experimental field

Each data indicates the nutritious elements contents in different soil layers. 
Table 1. Soil conditions of the experimental field.

\begin{tabular}{ccccccc}
\hline Year & $\begin{array}{c}\text { Soil layers } \\
(\mathrm{cm})\end{array}$ & $\begin{array}{c}\text { Organic Matter } \\
\left(\mathrm{g} \cdot \mathrm{kg}^{-1}\right)\end{array}$ & $\begin{array}{c}\text { Total N } \\
\left(\mathrm{g} \cdot \mathrm{kg}^{-1}\right)\end{array}$ & $\begin{array}{c}\text { Available N } \\
\left(\mathrm{mg} \cdot \mathrm{kg}^{-1}\right)\end{array}$ & $\begin{array}{c}\text { Available P } \\
\left(\mathrm{mg} \cdot \mathrm{kg}^{-1}\right)\end{array}$ & $\begin{array}{c}\text { Available K } \\
\left(\mathrm{mg} \cdot \mathrm{kg}^{-1}\right)\end{array}$ \\
\hline $2011-2012$ & $0-20$ & 13.2 & 1.1 & 148.8 & 33.0 & 128.6 \\
& $20-40$ & 5.6 & 0.6 & 60.5 & 7.3 & 50.0 \\
$2012-2013$ & $0-20$ & 20.3 & 0.9 & 124.5 & 21.4 & 133.3 \\
& $20-40$ & 9.6 & 0.4 & 42.0 & 7.5 & 52.6 \\
\hline
\end{tabular}




\section{Table 2 (on next page)}

Plant height of wheat under different treatments

Each data point indicates the average plant height of 5 repeats plants at different treatments. 
Table 2. Plant height of wheat under different treatments.

\begin{tabular}{cccccc}
\hline \multirow{2}{*}{ Year } & \multirow{2}{*}{ Treatment } & \multicolumn{4}{c}{ Plant height $(\mathrm{cm})$} \\
\cline { 3 - 6 } & & Pseudostem erection stage & Jointing stage & Booting stage & Maturity stage \\
\hline $2011-2012$ & TS & $17.8 \mathrm{a}$ & $29.7 \mathrm{a}$ & $60.3 \mathrm{a}$ & $69.2 \mathrm{a}$ \\
& TPS & $17.5 \mathrm{a}$ & $28.1 \mathrm{~b}$ & $58.6 \mathrm{~b}$ & $67.6 \mathrm{~b}$ \\
& TJ & $19.0 \mathrm{a}$ & $27.6 \mathrm{c}$ & $57.1 \mathrm{bc}$ & $66.4 \mathrm{~b}$ \\
& TPJ & $18.3 \mathrm{a}$ & $27.6 \mathrm{c}$ & $56.3 \mathrm{c}$ & $64.1 \mathrm{c}$ \\
& & & & $68.7 \mathrm{a}$ \\
& & & & $54.4 \mathrm{a}$ & $67.1 \mathrm{~b}$ \\
& TS & $19.1 \mathrm{a}$ & $27.1 \mathrm{a}$ & $51.3 \mathrm{~b}$ & $66.0 \mathrm{~b}$ \\
\hline
\end{tabular}

2 Note: Different letters in each column indicate significant differences among four treatments, assessed by 3 ANOVA $(\mathrm{P} \leqslant 0.05)$. TS, nitrogen topdressing at erecting stage; TPS, TS combined with paclobutrazol 4 application; TJ, nitrogen topdressing at jointing stage; TPJ, TJ combined with paclobutrazol application. 


\section{Table 3 (on next page)}

Wheat yield and yield components under different treatments

Each data point indicates the wheat yield and yield components in three repeats testing plots with different treatments. 
Table 3. Wheat yield and yield components under different treatments.

\begin{tabular}{|c|c|c|c|c|c|}
\hline Year & Treatments & $\begin{array}{l}\text { Spikes } \\
\left(\times 10^{4} \cdot \mathrm{ha}^{-1}\right)\end{array}$ & $\begin{array}{c}\text { Grains Per } \\
\text { spike }\end{array}$ & $\begin{array}{c}\text { Thousand grain } \\
\text { weight (g) }\end{array}$ & $\begin{array}{c}\text { Yield } \\
\left(\mathrm{t} \cdot \mathrm{ha}^{-1}\right)\end{array}$ \\
\hline \multirow[t]{4}{*}{$2011-2012$} & $\mathrm{TS}$ & $796.7 \mathrm{a}$ & $33.6 b$ & $39.2 \mathrm{c}$ & $8.8 b$ \\
\hline & TPS & $752.3 \mathrm{a}$ & $34.4 b$ & $39.4 \mathrm{bc}$ & $8.9 b$ \\
\hline & $\mathrm{TJ}$ & 798.9a & $36.2 \mathrm{a}$ & $40.6 \mathrm{ab}$ & $9.4 \mathrm{ab}$ \\
\hline & TPJ & $807.8 \mathrm{a}$ & $36.9 \mathrm{a}$ & $41.6 \mathrm{a}$ & $9.7 \mathrm{a}$ \\
\hline \multirow[t]{4}{*}{$2012-2013$} & $\mathrm{TS}$ & $829.4 \mathrm{a}$ & $33.3 \mathrm{bc}$ & $28.0 \mathrm{~b}$ & $7.5 b$ \\
\hline & TPS & $834.9 a$ & $32.9 \mathrm{c}$ & $27.8 b$ & $7.6 b$ \\
\hline & $\mathrm{TJ}$ & $806.0 \mathrm{a}$ & $35.8 \mathrm{ab}$ & $31.7 \mathrm{a}$ & $7.8 \mathrm{ab}$ \\
\hline & TPJ & $823.4 \mathrm{a}$ & $36.7 \mathrm{a}$ & $30.5 \mathrm{ab}$ & $8.1 \mathrm{a}$ \\
\hline
\end{tabular}

2 Note: Different letters in each column indicate significant differences among four treatments, assessed by 3 ANOVA $(\mathrm{P} \leqslant 0.05)$. TS, nitrogen topdressing at erecting stage; TPS, TS combined with paclobutrazol 4 application; TJ, nitrogen topdressing at jointing stage; TPJ, TJ combined with paclobutrazol application. 


\section{Table 4(on next page)}

Spike differentiation of wheat under different treatments

Each data point indicates the average performance of 5 repeats in spike differentiation indexes under different treatments. 
Table 4. Spike differentiation of wheat under different treatments.

\begin{tabular}{|c|c|c|c|c|c|}
\hline Year & Treatments & $\begin{array}{c}\text { Differentiation Spikelet } \\
\text { number }\end{array}$ & $\begin{array}{c}\text { Differentiation Floret } \\
\text { number }\end{array}$ & $\begin{array}{c}\text { Floret number } \\
\text { differentiated from } \\
\text { stamen and gynoecium }\end{array}$ & $\begin{array}{c}\text { Floret number } \\
\text { differentiated from } \\
\text { connectivum }\end{array}$ \\
\hline \multirow[t]{4}{*}{ 2011-2012 } & TS & $20.8 \mathrm{a}$ & $140.8 \mathrm{~b}$ & $118.4 \mathrm{~b}$ & $52.2 \mathrm{c}$ \\
\hline & TPS & $19.2 b$ & $138.2 \mathrm{~b}$ & $102.2 \mathrm{c}$ & $56.8 \mathrm{~b}$ \\
\hline & $\mathrm{TJ}$ & $20.8 \mathrm{a}$ & $145.4 \mathrm{ab}$ & $115.4 \mathrm{~b}$ & $59.0 \mathrm{~b}$ \\
\hline & TPJ & $20.4 \mathrm{ab}$ & $150.2 \mathrm{a}$ & $123.6 \mathrm{a}$ & $62.6 \mathrm{a}$ \\
\hline \multirow[t]{4}{*}{$2012-2013$} & TS & $19.4 \mathrm{a}$ & $148.8 \mathrm{a}$ & $99.4 \mathrm{~b}$ & $67.0 \mathrm{~b}$ \\
\hline & TPS & $18.4 \mathrm{~b}$ & $141.8 \mathrm{~b}$ & $96.4 \mathrm{~b}$ & $66.2 b$ \\
\hline & $\mathrm{TJ}$ & $18.8 \mathrm{ab}$ & $150.4 \mathrm{a}$ & $112.6 \mathrm{a}$ & $87.6 \mathrm{a}$ \\
\hline & TPJ & $19.0 \mathrm{ab}$ & $149.6 \mathrm{a}$ & $113.8 \mathrm{a}$ & $85.8 \mathrm{a}$ \\
\hline
\end{tabular}

2 Note: Different letters in each column indicate significant differences among four treatments, assessed by

3 ANOVA $(\mathrm{P} \leqslant 0.05)$. TS, nitrogen topdressing at erecting stage; TPS, TS combined with paclobutrazol

4 application; TJ, nitrogen topdressing at jointing stage; TPJ, TJ combined with paclobutrazol application. 


\section{Table 5 (on next page)}

The correlation between (IPA+ZR) content and floret number

Each data point indicates the correlation coefficient of 12 runs between (IPA+ZR) content and floret number differentiated from connectivum, stamens and pistils. 
Table 5. The correlation between (IPA+ZR) content and floret number. **P $<0.01$ and $* P<0.05$.

\begin{tabular}{lll}
\hline content of (IPA+ZR) & $\begin{array}{l}\text { florets differentiated from } \\
\text { connectivum }\end{array}$ & $\begin{array}{l}\text { florets differentiated from } \\
\text { stamen and gynoecium }\end{array}$ \\
\hline 0 day after flowering & $0.825^{* *}$ & $0.855^{* *}$ \\
3 days after flowering & $0.685^{*}$ & $0.63^{*}$ \\
6 days after flowering & $0.766^{* *}$ & $0.725^{* *}$ \\
9 days after flowering & $0.600^{*}$ & $0.683^{*}$ \\
12 days after flowering & $0.913^{* *}$ & $0.875^{* *}$ \\
15 days after flowering & $0.695^{*}$ & 0.549 \\
\hline
\end{tabular}

2 Notes. *, ** significant at the 0.05 and 0.01 probability levels, respectively, ns, no significant. Each data point 3 represents the average of the measured data.

4 
Figure 1 (on next page)

Dynamic of endogenous hormone levels in ears during spike differentiation

E Each data point indicates the average performance of 5 repeats in phytohormone contents with different stages. 



Figure 1 Dynamic of endogenous hormone levels in ears during spike differentiation. *, ** significant at the 0.05 and 0.01 probability levels, respectively, ns, no significant. Each data point represents the average of the measured data. 
Figure 2

IPA and ZR content of spikes under all treatments at different stages

Each data point indicates the average performance of 5 repeats in spike with different treatments during all flowering stage. 


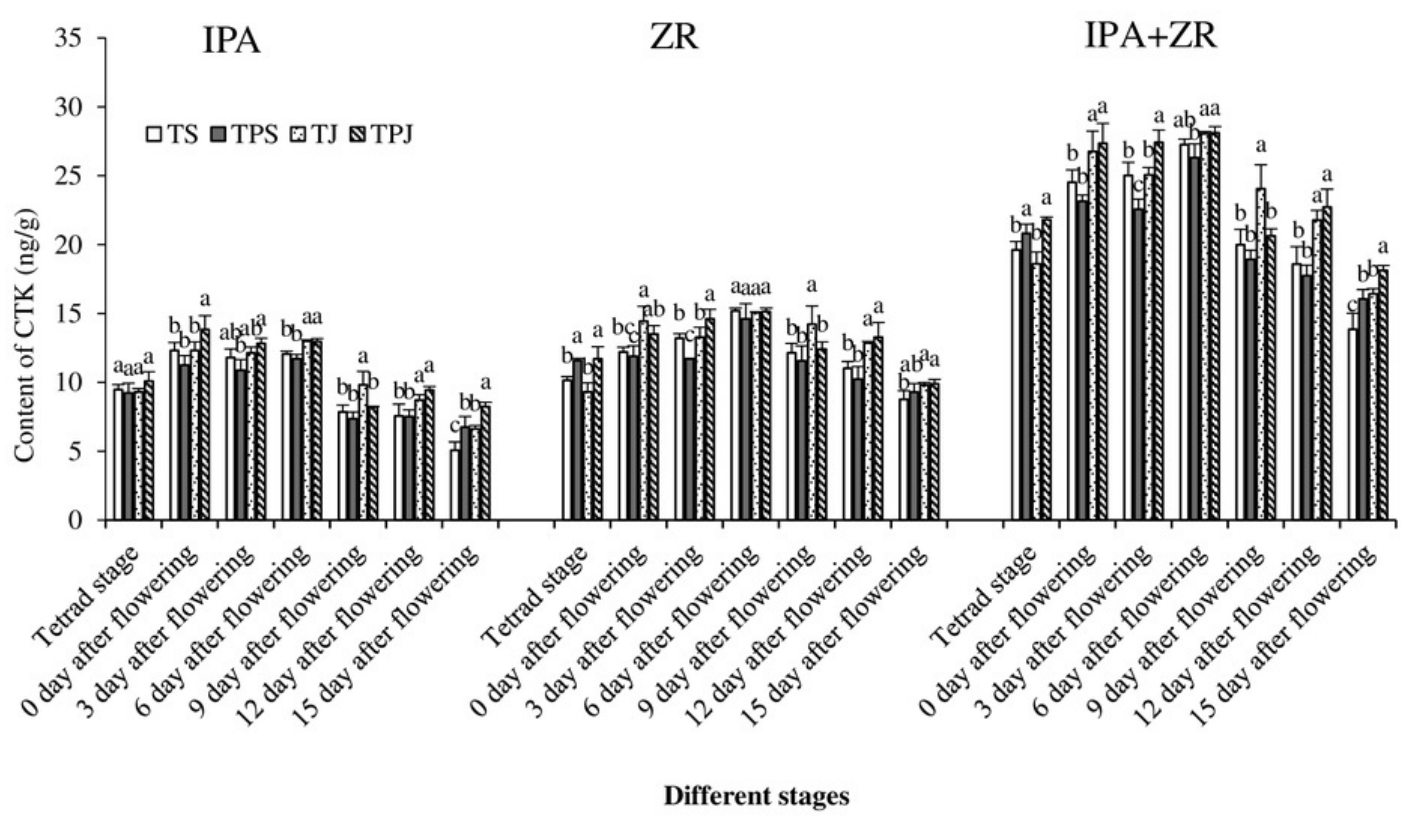

Fig.2. IPA and ZR content of spikes under all treatments at different stages. Different letters indicate significant differences among four treatments, assessed by ANOVA $(P \leqslant 0.05)$. 
Figure 3

The changing trend of relative expression of TACKX2.2 at different stages

Each data point indicates the average performance of 3 repeats samples after randomly choosing with all treatments at different spike differentiational stages 


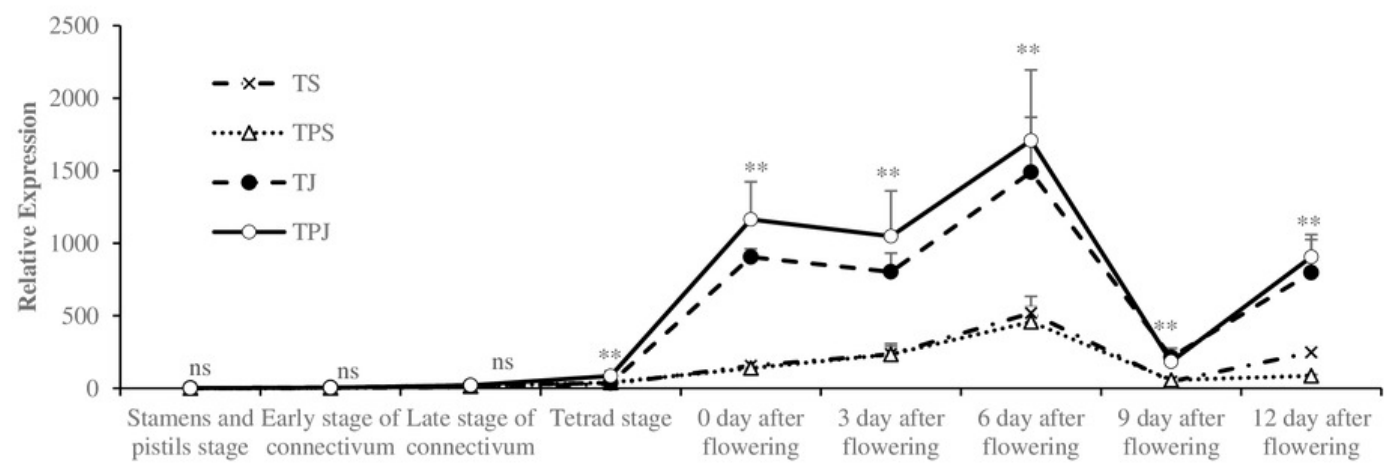

Stages of spike differentiation

Figure 3 The changing trend of relative expression of $T A C K X 2.2$ at different stages. *, ** significant at the 0.05 and 0.01 probability levels, respectively, ns, no significant. Each data point represents the average of the measured data. 